\title{
Towards room-temperature superconductivity
}

The past few weeks have witnessed an astonishing preoccupation with the hitherto esoteric and inaccessible phenomenon of superconductivity. To banish electrical resistance may be the contemporary equivalent of the philosophers' stone. Nature correspondents say how it seems to them.

\section{German ambivalence} Munich

WEST Germany is in a curious state of confusion about oxide superconductivity. Most people are impressed that the first dramas were acted out at the IBM laboratory at Zurich, where the tunnelling electron microscope won a Nobel Prize for its inventors only a year ago. Many of those working in the field are away this week, still on the way back from the American Physical Society's meeting in New York. The meeting of the German Physical Society earlier in March appears not to have satisfied all curiosity.

For the time being, however, the Technische Höchschule at Darmstadt seems to be in the lead. Frank Steglich and his group have been looking at the feasibility of making Josephson junctions of the new materials; their tentative conclusion is that the boundaries between grains in the ceramic materials are responsible for most departures from superconductivity, which is an incentive to make materials with bigger crystals.

The Nuclear Research Centre at Karlsruhe supports two active groups, as does Munich. Both centres are playing with the substitution of one rare-earthy element for another. Karlsruhe is eager to measure electrical properties. The University of Giessen is also active.

Most workers in the field are surprised at the speed with which events are moving. Professor Saemann-Ischenko at the University of Erlangen is struck by the advance towards industrial applications of the new materials. Steglich, at the University of Darmstadt, says that West Germany was "a little bit behind" at the beginning, but that the field is still wide open.

Steven Dickman

\section{Japanese gird loins}

\section{Tokyo}

AN heroic effort is under way here to develop high-temperature superconductors before the United States.

At the semi-annual meeting of the Physical Society of Japan in Nagoya on 28 March, an afternoon session on hightemperature conductivity was swamped with presentations by more than 50 speakers from government, industry and the universities. Talks were strictly limited to 10 minutes, including discussion, and peo- ple jammed the aisles and spilled out of the doors of the conference hall as they jostled and craned to hear the proceedings, which continued well into the night under the glare of television camera lights.

It is less than four months since a group of researchers at Tokyo University confirmed superconductivity at about $30 \mathrm{~K}$ in a copper oxide ceramic. But research is already under way on a broad front. Some speakers talked on crystal structure and theory, others reported more practical findings: researchers from NEC Corporation presented evidence of the alternating current Josephson effect in a yttriumbarium oxide at about $90 \mathrm{~K}$; Nippon Telephone and Telegraph (NTT) reported superconductivity at $90 \mathrm{~K}$ in a new lanthanum-barium-copper oxide, an important discovery as lanthanum is much cheaper than yttrium; and Fujikura Densen, an electric cable manufacturer, showed pictures of a crude loop of wire fashioned from the new ceramics.

"I used to play golf every weekend until this happened", lamented Professor Shoji Tanaka, leader of the Tokyo University group, as he took a breather for coffee during the marathon session. Now Tanaka's time is fully occupied shuttling back and forth between meetings and conferences both inside and outside Japan.

Tanaka is particularly excited by his group's discovery that ceramics doped with paramagnetic rare-earth elements (such as erbium and holmium) rather than yttrium retain their superconductivity and have similar critical temperatures to the yttrium ceramics. He thinks this finding may lead the way to ceramics with high critical currents, thereby opening up a treasure chest of applications, including superconducting magnets, energy storage devices, superconducting computers and cheap magnetically levitated trains (the Nagoya session happened to be held at the same time as the Japan National Railways carried out the first test run of a prototype train levitated by conventional superconducting magnets - the train cost about $\$ 10$ million (Y1,500 million) to build).

But Tanaka worries that the race to develop such applications may lead to a conflict with the United States, similar to problems now seen in the chip and supercomputer trade. IBM and most other US companies drastically scaled down their research on Josephson junctions in 1983, partly because of the complications of cooling with liquid helium, but Japanese companies such as Hitachi and NEC have forged ahead. Last year, Japan's Research and Development Corporation awarded a $\$ 10$ million grant for five years to Professor Goto of Tokyo University to develop a superconducting magnetic flux computer under the ERATO programme (see Nature 324, 507; 1986).

A member of the editorial board of the Japanese Journal of Applied Physics echoed a similar sentiment to Tanaka when he announced during the Nagoya session that he, not an American, would correct the English of the flood of papers the journal had received. Although said as a joke, it does reflect the keen sense of competition with the United States.

Government ministries have also been quick to spot a potential winner. The Science and Technology Agency (STA) set up a committee in late February, drawn from universities, industry and government laboratories, to organize symposia, analyse research trends and publish reports on the new superconductors. Funding for the commiteee's activities comes not from the government but from a group of about 40 companies, including electronics giants, mining concerns and electric cable manufacturers, who have contributed Y200,000 each to the fund.

A similar committee has been set up by MITI, the Ministry of International Trade and Industry, although, according to Tanaka, there are more members from industry than in the STA commitee (Tanaka serves on both). MITI is also considering applying the new superconductors in its energy-saving Moonlight project, for example, by developing energy-storage devices.

Last year, the Ministry of Education, Science and Culture thought that a special project on superconductivity headed by Professor Nakajima of Tokai University (formerly of Tokyo University) was a failure. Now the ministry has decided to extend the three-year programme by an extra year. But, apart from this small commitment, no major government funds have yet been assigned to research on the new superconductors. Undoubtedly the bulk of the drive and support for research will come from industry. And judging from Nagoya, research in that sector is already well ahead. David Swinbanks

\section{Mild enthusiasm}

\section{Washington}

THE enthusiastic attendance at the latenight meeting of the American Physical Society, in New York on 19 March, was proof enough of people's determination to break the record in the race for the superconductor with the highest transition temperature. But in the absence of a simple explanation of the new results, researchers are relying on inspired guesswork 
and empirical extrapolation in the design of new materials.

Most people appear however to agree that, for the time being, the starting point for the new wave of excitement is the discovery (at the IBM laboratory at Zurich, where tunnelling electron microscopy was first made a reality) that lanthanum copper oxide can be superconducting. Since then, yttrium has been successfully substituted for lanthanum, as have been lutetium (at Brookhaven) and gadolinium (at the Sandia Laboratories).

Dave Ginley of Sandia makes no bones about it: it is possible to make a whole series of crystalline structures by substituting one rare earth for another. The small variations of crystal structure caused by the different ionic radii of the constituents yield solids with different properties. The trick, for the time being, is to ring the changes that work in the right direction, that of a higher transition temperature.

Meanwhile, more and more attention is being paid to techniques of fabrication. The current-carrying capacity of the materials so far made is no more than one ampere per $\mathrm{mm}^{2}$, rather less than is usually carried by a domestic power cable. Jim Smith, director of the Center for Materials Science at the Los Alamos National Laboratory, noting that the materials so far constructed are little better than "compressed powders", argues that the future must lie in more careful heat treatment of the ceramics to yield materials more like glasses that will carry a higher current density.

Meanwhile, much attention is being paid to techniques for making flexible stranded cables out of brittle ceramics. Much of the technology of the classical superconductors turns out to be relevant: niobium-titanium and niobium-tin are hard and glassy in themselves, but can be extruded into fine flexible wires when embedded in copper. Curious as it may seem, nobody working in this new field is dismayed at the prospect of putting the new materials to large-scale use. The question is when, and at what temperature.

David Lindley

\section{Late starters}

BRITISH research groups are working fast to catch up with their Japanese and US counterparts in the race to exploit the new superconducting ceramics. But many are worried that cuts in grants have undermined their efforts before they start. In just two months, researchers have switched from long-standing projects to the novel topic; all the groups that have declared themselves have succeeded in synthesizing and characterizing the compounds reported by Chu in Houston and other workers.

At a meeting last week of the Rare Earth and Actinides group sponsored by the Science and Engineering Research Council (SERC) at Birmingham, three progress reports showed the strides taken in the past weeks. A collaboration between the Universities of Warwick, Durham and Cambridge and the Rutherford Appleton Laboratory (RAL) has succeeded in characterizing the crystal structure of the lanthanum-barium ceramic $\left(\mathrm{LaBaCuO}_{4}\right)$ using the ISIS neutron facility at RAL. This high-resolution facility gives them, they believe, a unique advantage over groups elsewhere, and has revealed fine alterations in structure and phonon characteristics that coincide with changes in electrical behaviour.

The University of Birmingham boasts another collaboration, all on one site, using various skills in sample preparation and low-temperature work already available. The researchers there have measured the magnetic flux through a cylinder of the yttrium-barium ceramic $\left(\mathrm{YBaCuO}_{4}\right)$ and shown that it is quantized, which confirms the superconducting nature of the material. The value of the quantum is not yet certain, but their result means that there must be persistent currents, and they say that the resistance of the sample is less than $10^{-11} \mathrm{ohms}$.

Other groups not represented at the meeting have also made rapid progress. At Cambridge, several groups are involved. They are relying on proven expertise in the manufacture of high-purity single crystals to obtain samples that will allow them to investigate the microscopic properties that cause the superconductivity. With a history in the preparation of the related ceramics $\mathrm{LaNiCuO}_{4}$, the department of metallurgy at Imperial College London, is working with the physics department, where they have long experience in composite superconductors. They are particularly interested in the effects of grain boundaries in these compacted materials. Research is also under way at Oxford and Bristol.

All those involved are worried that the squeeze on university budgets has left them in a weakened position. One says that the new opportunity is also an example of the effect of the drive for efficiency in universities, in which the nature of longterm research has been forgotten. Compared with companies such as AT\&T Bell and IBM, which can put large numbers into the field at short notice, Dr Chris Muirhead of the University of Birmingham believes only a handful of researchers can become involved in British universities. The present consensus is that staffing and not equipment is the problem - most laboratories are using existing equipment, sometimes hastily adapted. The general view is also that British research is best concentrated on fundamental physics and not on the race for higher temperatures.

SERC can offer little more than sym- pathy. The last round of grant applications came before the new potential was realized. Now $£ 8$ million overcommitted, the next round of SERC grants is virtually cancelled except for specific initiatives into which superconductor research may be slotted. According to John Farrow, secretary of the SERC physics committee, the committee recognizes "that this research must be supported urgently"; he says that a case for supporting the research out of the '21st Century Materials Initiative' is being put together. But in the present round, he expects support to be in the region of $£ 200,000$ - enough to support one or two key groups. He says that the council expects to be able to support larger applications by about September.

SERC has not yet promoted any combined university/industry research programme, but it is considering setting up a joint meeting of interested parties. The LINK scheme of the Department of Trade and Industry (DTI), designed to stimulate such cooperation, includes a programme for electronic materials, but the relevant committee has yet to meet. A spokesman for the DTI said that there was also the opportunity for collaborative schemes under the Support for Innovation project, citing materials development as an appropriate area. He went on to say that "this work is still at the basic research level, not with any specific applications at the moment", so that DTI involvement was not necessarily appropriate just now. Given the enthusiasm for the new opportunity at the New York and Nagoya meetings, it may be that British companies will be left behind.

\section{Anything goes?}

IN the race to reach the record temperature for the onset of superconductivity, almost anything goes. A field developing as rapidly as this is fertile ground for rumour, and it is often difficult to distinguish fact, tentative result and speculation. The China People's Daily of 19 March reported a spectacular advance with the onset of superconductivity at $215 \mathrm{~K}$, though the transition is said to be very broad, with a midpoint at $93 \mathrm{~K}$.

If true, this work from the Chinese Academy of Sciences represents a substantial $100 \mathrm{~K}$ advance on previously reported records. Still more remarkable is the claim from Dr Kozo Ohara's group at Kagoshima University in Japan of the possibility of superconduction at $14^{\circ} \mathrm{C}$ - room temperature. This result, originally published in the Japanese daily newspapers on 18 March, was hotly debated at the recent meeting in Nagoya (see above) as zero conductivity was not measured, although other indicators of superconductivity (the Meissner and Josephson effects) were. Experts at the conference said it was "too soon to call this superconductivity". R.P. 